\title{
The Application Of A Conversion Method In A Confrontational Pattern-Based Design Method Used For The Evaluation Of It Systems
}

\author{
Witold Chmielarz \\ University of Warsaw, \\ Faculty of Management, \\ ul. Szturmowa 1/3, 02-678 Warszawa, Poland \\ Email: witek@wz.uw.edu.pl
}

\author{
Marek Zborowski \\ University of Warsaw, \\ Faculty of Management, \\ ul. Szturmowa 1/3, 02-678 Warszawa, Poland \\ Email: mzborowski@wz.uw.edu.pl
}

\begin{abstract}
The objective of this paper is to examine application possibilities of a conversion method in a new confrontational pattern-based design method used for IT systems evaluation. First, the authors present characteristic features and assumptions of the new methodology. Next, they conducted a study verifying the application of this methodology in the analyses preceding the execution of the project aiming at creating a new comparison engine, based on the model which received the highest scores in the evaluation. The results of the study were analysed, and the authors examined their usefulness with regard to the application of the presented method.
\end{abstract}

\section{INTRODUCTION}

I $\mathrm{N}$ THIS article the authors present an application of the conversion method for the evaluation of websites. The conversion method may be considered as an extension of the novel methodology to design IT systems. The method is based on the averaging of distances from the average results of the surveys concerning the quality of IT systems [4]. This article shows that the application of the conversion method to the confrontational pattern-design method is possible. It refers both to the activities of project teams and on the other the modern methods of design solutions for design through the service (Service Desig) [10]. The main recommendations of this type are methods $[3,6,12,13]$ : focus on the needs of the user; full cooperation of the parties during the project, to present the full implementation of the service over time; formalization and a peculiar "materialization" of all elements of the service in a way comprehensible to the user and comprehensive account of the trial of the service by a single contractor.

They have one fundamental flaw: they do not provide models, procedures and practices which are the required contribution to the theoretical knowledge. Thus, they are not embedded in a broader economic or praxeological context. Therefore, they cannot be used for the purpose of the optimization of investment in IT (especially services), formulation of new service projects (based on the added value for the customer global and multicultural), and the implementation of projects

This work was not supported by any organization that allows these project to be immersed in the realm of operation systems as much as possible. This is particularly important for electronic commerce tools.

The integration of these solutions with basic assumptions of modern management methods and some of the best proven traditional solutions can bring, as it seems, very good results with regard to creating design patterns. This conclusion is supported with a number of experiments conducted by the authors during the research into the assessment of e-business [2] and the possibility to use the findings in system designing. In the study the Authors used an iterative approach to identify ex ante needs of the user and confront them with the ex post experiences resulting from a deep analysis of the existing IT solutions of Confrontational Pattern-Based Design Method.

The basic assumptions and recommendations Confrontational Pattern-Based Design Method refer to the concept of Service Design, on the one hand, and Agile Design methods on the other [5]. They are as follows:

- in many cases user's requirements, even in the case of an informed client, are dominated by existing habits connected with the IT systems used in the organization: in the clients' opinion the questions concerning additional functionalities introduce elements of ambiguity, or even contradiction,

- project schedule becomes the result of negotiations between the user, expecting to reduce the time of the realisation of the project, or even be provided with the finished product immediately, and the possibilities of the contractor and his desire to offer a product which is of higher quality than the existing solutions,

- iteration between the initial recognition of the user's needs (even if they tend to be reduced to the experience of the previous installation), and best practices derived from the analysis of the existing solutions on the market; each successive iteration is a compromise bringing us closer to the final solution,

- there are methods of identifying best practices, consistent with the scientific basis of the evaluation of IT systems (and common sense); we should aim at constant 


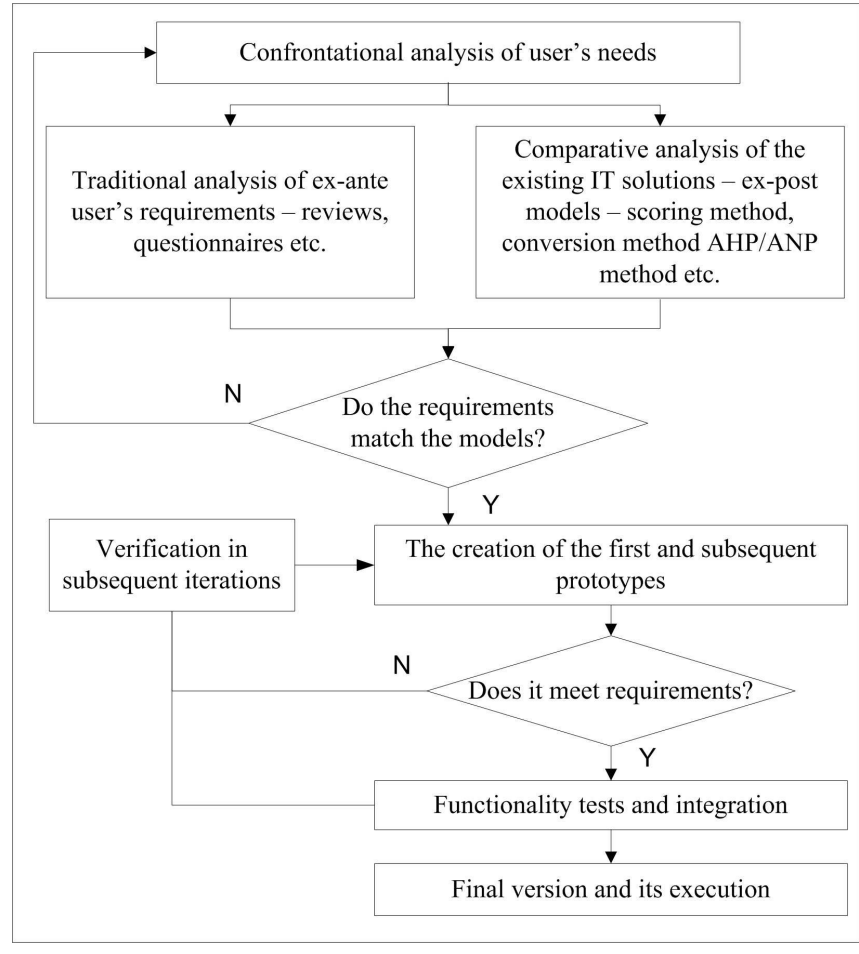

Fig. 1. Basic phases of the life cycle of the project in CPD model Source: on the base of [5]

improvement or creation of an IT system which allows for automatic selection of the method best suited to a particular decision-making situation,

- the user shows a specific tendency to overcomplicate systems, thus, we should aim at their greatest simplicity at the level of design, content, service and methods of solving basic design problems,

- parallel analysis of the user's requirements - on the one hand, the application of traditional analytical methodologies (questionnaires, interviews, conversations, ...), on the other, consideration of the user's evaluation of the existing systems in order to extract certain components which can meet his needs in the best possible way,

- coordination of the language describing design requirements with the assessment criteria of existing solutions,

- ongoing integration of selected components in accordance with previous arrangements in the present version of the project,

- solving, by way of negotiation, confrontational requirements resulting from the projection of the user's requirements, performance and usage analyses as well as expert requirements resulting from the best practices of completed projects in the same area.

The life cycle of the project according to CPD model (see: Figure 1), consists of four basic phases: confrontational analysis of the user's needs - parallel examination of the needs of the final user and of the existing IT solutions in the field. Based on the list of the best solutions, we create a project based on the optimal design patterns used in the existing portals. In the case of differences - negotiations with users which aim at bringing their position closer to the position resulting from the analysis of best practices; on this basis we create a prototype of an IT system - subsequently, it is presented to the client; in the case it does not meet the user's expectations - introduction of changes, creation of another prototype - presentation of the prototype to the user; in the case of fulfilling requirements - testing stage; functionality tests - subsequent versions presented to the client are tested before next modifications, which client may suggest at this stage. In case of doubts, we return to the creation of the next prototype and working on the final version of the project; the last iteration leads to the creation of the last, complete version of the project, which is then executed.

Methodology of the Confrontational Pattern-Based Design Method concerns mainly small and medium-sized e-commerce projects. It assumes full access to the existing software, from the user's perspective, and such a situation is taking place in the Internet. Apart from the classical analysis of the user's requirements, the practical approach consists in the examination of the existing solutions enabling: specification and accurate research into the area in which the software works, creating a ranking of IT solutions existing on the market, identification of the features which make particular solutions better than others.

However, there are concerns regarding: the creation of a coherent methodology which needs to be applied in the examination of the needs of a user of existing IT solutions, interpretations of findings of practical analyses, the necessity of taking into account the high dynamics of technological innovation in this field, the necessity of developing the mechanism of negotiations of the proposed solutions with the end user.

\section{Assumptions OF THE STUDY}

The issue of creating a project of a comparison site may be used as an example of the application of this method. The findings of a research company Tradedoubler [9] shows that Polish clients use comparison sites more and more frequently, anticipating constant growth of e-commerce (Poland and Czech Republic noted over 30\% increase of internet sales in 2012, while the average in Europe is 22\% [7]). The determinants of the success seem to be: the novelty effect, limited financial resources, which consumers may spend on shopping, promotional activity of comparison sites, the growing awareness of the opportunities posed by internet shopping, and the price, which is a key criterion in the case of buying branded goods. The destimulators are mainly phenomena such as:

- not all shops in Poland, especially new ones, present their offers on comparison sites,

- offers are not continuously updated,

- errors concerning the presented product price,

- there is no active verification of the prices provided by the shops [5]. 
The most popular software of this class on the market are: Ceneo.pl, Skapiec.pl, Nokaut.pl and Okazje.info.pl. The client verifies the price, brand of a product, reputation of a shop, client's opinions, and subsequently, based on the available data, he or she chooses the most attractive offer. At present, comparison sites are widely known and more commonly used - therefore, they prove to be very useful in conducting the mass research into the needs of the so-called average user of the Internet.

The assumptions of the study were as follows:

- the objective of the study is to design an online comparison service so that it meets the users' needs in a way which is optimal in terms of the qualitative characteristics: functional, technological, etc.,

- we should analyse users' requirements concerning the basic usability parameters of the portal. The study's objective is to indicate the parameters which are most important from the point of view of the websites' clients (considering the class of electronic agents),

- based on the above findings, we create a list of the most important evaluation criteria of the existing comparison websites,

- the list of criteria is used for individual evaluation of comparison websites known to users (one user can evaluate more than one website),

- the group of respondents is not chosen at random, it belongs to the class of convenient samples as the respondents are students of the selected universities in Warsaw (Faculty of Management of the University of Warsaw and Faculty of Information Technology of the Academy of Finance and Business Vistula); they represent all types of studies (B.A., B.Sc., M.A., PhD studies),

- the evaluation will be standardized according to the tenpoint scale used to examine other types of IT systems,

- the results of the analysis of user requirements will be confronted with the evaluation of the characteristics of the existing comparison websites in order to identify the best possible implementation of those characteristics which are most important from the user's point of view,

- the analysis will be performed first by a scoring method, and, next by conversion method for minimization of subjectivity and thus their realignment,

- multiplying the preference scale by the table of results of the scoring analysis will allow for the realignment of the findings with the application of relations among particular criteria,

- the realignment will result in finding the design patterns of comparison websites which are considered best from the point of view of management, and which may be used in the creation of the design of the website of this class.

Initially, among the randomly selected five students of the Faculty of Management of the University of Warsaw and Academy of Finance and Business Vistula, declaring the use of comparison websites for making purchases, the authors carried out a pilot study concerning the factors which are most important when using software of this class. After the users' suggestions and as a result of standardization (unification of terminology and concepts of particular categories proposed by them), the following groups of characteristic features have been identified: design (visualization), information presented on the site and the ease of navigation, text search, data operations: selection (filtering) and sorting the results according to selected criteria and additional functionalities used for increasing user-friendliness.

Conclusions from the observation of students' behaviour supplied the initially established sets of features with the detailed criteria and subcriteria, which were thoroughly discussed with the respondents before placing them on the list used in the evaluation. The final list of criteria included:

- visualisation, information available on the website and the ease of navigation: brand awareness (the ease of memorizing data and reasons why we like the website), main page (readability and clarity of the main page, the ease of navigation and finding particular functions), the consistency of graphic elements, clearly marked colours, matching colours of elements, background colouring, icons symbolizing categories of products, colours and clarity of the text, carefully selected pictures of good quality, etc.), photo gallery (large, readable and clear images, which do not obscure navigation and present the actual features of the product etc.), completeness of information (characteristic features, minimum/maximum price, product image), clarity (appropriate font size, distinct colouring, the appropriate distribution of elements on the website), avoiding distracting elements (too much advertising, excessive number of photographs, etc.), opinions about shops (logo, delivery time, minimum price, clients' opinions), product reviews (if they are available, in what form, whether they meet clients' requirements), comparison engines (operating according to features specified by a client - e.g. price, number, delivery time), the ease of using categories (availability: lists, subcategories, characteristic features, etc.), the form of presentation of the product list (lists, different views, presentation according to the product features, icons, photos), rankings of products/shops (position in the ranking of shops/product categories), suggesting products (prompting — the latest model, at a similar price, other customers also bought ..., etc.);

- functionality of the text search (dynamic search of the selected product, without the necessity of looking through many categories): the accuracy of search results (the name of the product, the name of the product + producer, etc. combinations), prompting (lists displayed during the search, text field with autocomplete: prompting the name in the early selection stage, etc.), spellchecker (automatic correction of spelling);

- filtering and sorting results (simple and easy selection of products): filtering functionality (a large number of criteria, speed, limitations on operations which may be 
performed by a client; the possibility of creating complex selection rules, etc.), sorting functionality in the product list (criteria of ordering and its combinations), sorting functionality in the list of shops (map, city, list according to prices);

- additional functionalities (functions improving usability) for the user (individually for websites): ordering at the level of a comparison site, memorizing a list of products, creating sets of products, loyalty program, the possibility of using mobile applications, price alert, tracking the changes concerning your favourite products (prices, characteristics).

In November 2013 the authors conducted surveys in the selected universities. Over 110 people filled the survey. Among the survey participants: women constituted $2 / 3,1 / 3$ of respondents were men. Most people, $80 \%$, were in the age group of 18-25 - typical for students of full-time studies and $15 \%$ from the age group of 26-35 - characteristic of students of parttime studies. The participation of people over 35 years of age was small $-5 \% .58 \%$ of the respondents were representatives of the cities with over 500,000 inhabitants, $22 \%$ of towns with $10-100,000$ inhabitants, only $6 \%$ were from rural areas. Over $60 \%$ declared having secondary education, $28 \%$ were students of BA studies and $7 \%$ of MA studies. Three-quarters of the group declared the status of a student, $15 \%$ are employed in the private sector, $6 \%$ in the public sector and $4 \%$ are selfemployed. Over a third of the sample belongs to the income group with over PLN 4,000 per month, 28\% 2,000-2,500, 23\% to PLN 1,500 , and $12 \%$ to the remaining groups.

\section{ANALYSIS RESULTS BY SCORING METHOD AND THEIR IMPLMENTATION IN THE DESIGN}

The first part of the survey available in the Internet and distributed in its traditional form was used to verify the importance and relevance of the list of criteria established in the interviews and direct discussions (information analysis) with clients of comparison websites (students) in a pilot survey. For all respondents, all the criteria connected with visualization, information contained on the website and the ease of navigation turned out to be the most important factors $(34.2 \%)$. The second place was taken by the functionalities of the text search $(33.8 \%)$; the last position $(32.0 \%)$ was taken by the functionality of filtering and sorting results and additional functions improving usability. The differences in those groups were not very significant (up to 2 percentage points). For particular selected criteria, the differentiation did not appear to exceed (to a great extent) the observed results. The difference between the highest and the lowest scores amounted to $2.1 \%$.

Relatively highest scores were assigned to the accuracy of search results $-5.68 \%$ and the completeness of information $-5.58 \%$; the lowest were given to: suggesting products $3.58 \%$ and additional functionalities $-3.83 \%$. In total, this indicates the proper use of this tool (compatible with the objectives behind its creation) and its use in an elementary, rather than extended, range. In the case of website comparison websites, the evaluation of visualization criteria turned out to be very high - the graphic designs of home page obtained the score of $5.56 \%$.

In the evaluation of the usability of criteria, $40 \%$ of responses were very high scores and about $31 \%$ of responses claimed that the criteria selected for the study were good: this means that almost 3/4 of criteria specified in the pilot survey are regarded as accurate. On average, only $3 \%$ of the respondents considered the criteria as poorly matched to the assessment of comparison websites. Small differences in the average scores do not induce the authors to reject any of the criteria. A similar situation occurs when we refer the average values of the obtained scores to the maximum possible score in the evaluation of comparison websites. In this way we obtained a list of functionalities of a comparison website which, from the users' point of view, best suits their expectations with regard to this type of service. Its importance has been verified by means of a survey conducted among the clients of selected comparison websites. All listed elements obtained more than $50 \%$ of the maximum possible value, so they may be applied in the ex post analysis of the existing comparison websites.

In the second part of the study, the authors conducted an examination of the comparison websites according to the previously adopted criteria. The examination analysed the four selected comparison websites which are the most popular among clients and the fifth one, which was selected individually by respondents. The first three websites: Ceneo, Skapiec and Nokaut have obtained a total score above the average; okazje.pl and individually chosen websites (different from the most popular ones (Cenuj.pl, Webkupiec.pl etc.)), are positioned below the average. Generally, there emerges one regularity which may be applied when establishing analytical characteristics for the project - it indicates which of the existing websites of this class can be used as a basic pattern to be imitated when creating a new website. Generally, we may conclude that Ceneo.pl will serve this purpose in the best way. However, the detailed analysis of the results is not so clear or univocal. In terms of the consistency of graphics, loyalty scheme and tracking the changes in the favourite products, the leading position is taken by skapiec.pl, in case of price alerts - Okazje.pl. Skapiec.pl, which takes a second position in the ranking, does not offer price alerts which are of considerable importance to clients. Okazje.pl, which takes the lowest place in the ranking, occupies the second position when we take into account the evaluation of the homepage and creating sets and a third place with regard to the photo gallery it presents on its website.

We can also consider individual sites taking into account the features which are evaluated as the best and the worst (see Table 1). In the most popular websites there occurs a puzzling consistency of the best and the worst scores. In other services some of the characteristics are beyond the scope of the list. Hence, we may assume that, basically, the most important elements of the comparison websites are: brand awareness, home page, consistency of graphic elements and the accuracy of search results. However, whenever a particular website feature receives the lowest scores, it points to the fact that 
potential customers attach great importance to this particular element. Therefore, avoiding distractions, lack of spellchecker (or inappropriate corrections) and lack or limited number of additional functionalities should be added to the list. Also, we must appreciate the three remaining, important elements: completeness of information, the ease of using categories and filtering functionality. Thus, the design of the optimal comparison website should take into consideration at least the set of criteria presented in Table 1.

We may also analyse the results of the examination considering the number of scores in particular categories. Ceneo.pl was a leader in the ranking because it obtained the greatest number of very good scores. Also, the greatest number of good scores was assigned to Skapiec.pl, which came second in the ranking. The comparison website: Okazje.pl obtained the largest number of satisfactory or poor grades, other comparison websites - unsatisfactory. Nokaut.pl does not distinguish itself in any category. This table shows that it would be best to refer to the design patterns of ceneo.pl and Skapiec.pl when creating a new comparison website.

Apart from the possibility of limiting the number of basic features important for the creation of a prototype - which results from the studies of the existing websites in this category, the presented study shows a high discrepancy between the initial, average results of the clients' opinions concerning comparison websites and their characteristic features and average scores obtained from the ranking of the most popular websites existing in the Internet (see Table 3). Based on the initial evaluations, the first three positions are taken by: accuracy of search results, completeness of information, and the design of the homepage. When we take into account the evaluations of website analyses, the most important factors are: homepage, views of the product list, consistency of graphic elements.

The same situation occurs in the case of other features of comparison websites. However, if we consider not the values of the total of evaluations, but average values from initial analysis and the ranking of websites, then the importance of the features resulting from evaluations from initial analyses, more or less coincides with the importance of the features shown by the ranking of websites. What is the reason of such great variances between the opinions concerning the usefulness and importance of particular criterion for the evaluation of the comparison website, and low scores of these features in the analysis of particular comparison websites? It seems that the situation is caused by the users' awareness of high requirements which it should meet and, on the other hand, dissatisfaction with the implementation shown on the websites of existing comparison engines. It is also a clear indication for the system designer - we should not use the readymade patterns in the cases where we observe high discrepancy between the user's expectations and the importance of the feature and its fulfilment. We should focus on these elements so that they are presented in the form which would meet the users' expectations.
IV. THE RESUlTS OF THE ANALYSES OF COMPARISON ENGINES BY MEANS OF A CONVERSION METHOD AND THE

\section{APPLICATION OF THE FINDINGS IN PROJECT WORKS}

The analysis by means of a scoring method (considered only from the point of view of a scoring analysis) faced the objections of far-reaching subjectivity [5]. The application of conversion method is an attempt to eliminate this subjectivity - the author's applied his own conversion method [14].

Here, we adopt the following assumptions: after constructing the experts' table of evaluations of particular criteria for each website, we need to perform the conversion with the established preference vector of the superior level criteria [2]. Next, the authors performs the transformation of the combined scoring table into the preference vector (first converter).

The next steps are:

- constructing a matrix of distances from the maximum value for each criterion in every website, establishing the maximum value; establishing the matrix of the distances from the maximum value, calculating the average distance from the maximum value for each criterion,

- as a result of the above operation, constructing a matrix of differences in the distance from the maximum value and the average distance according to criteria,

- for each bank website: constructing conversion matrices - modules of relative distances of particular criteria to remaining criteria (the distance from the same criterion is 0 ), the obtained distances below the diagonal are the converse of the values over the diagonal,

- averaging criteria conversion matrices - creating one matrix of average modules of values for all criteria,

- transforming the conversion matrix of criteria into a superior preference matrix (calculating squared matrix, adding up rows, standardization of the obtained preference vector; repeated squaring, adding up rows, standardization of preference vector - repeating this iteration until there are minimum differences in subsequent preference vectors).

As a result of the above operations we establish a criteria conversion matrix.

Subsequently, the author performed a transformation of the scores presented by experts on the level of a matrix specifying expert websites' evaluations for particular criteria (second converter) [14]. The results have been obtained in an analogical way:

- constructing a matrix of distances from the maximum value for each criterion and each website establishing the maximum value; establishing the matrix of distances from the maximum value,

- calculating the average distance from the maximum value for each website,

- constructing a matrix of the differences of deviations from the maximum value and the average distance of the features from the maximum,

- for each criterion: constructing a matrix of transformations (conversions) of the differences of the average distance from the maximum value between the websites, 
TABLE I

THE MAP OF THE WEBSITE CRITERIA WITH THE HIGHEST AND THE LOWEST SCORES (WHERE: G - BEST-RATED FEATURES, B - WORST-RATED FEATURES)

\begin{tabular}{|l|c|c|c|c|c|}
\hline Description/Website/Evaluation & Ceneo & Nokaut & Skapiec & Okazje & Other \\
\hline Brand awareness & $\mathrm{G}$ & $\mathrm{G}$ & $\mathrm{G}$ & & $\mathrm{B}$ \\
\hline Homepage & $\mathrm{G}$ & & & $\mathrm{G}$ & $\mathrm{G}$ \\
\hline Consistency of graphic elements & & $\mathrm{G}$ & $\mathrm{G}$ & $\mathrm{G}$ & \\
\hline Photo gallery & & & & $\mathrm{G}$ & \\
\hline Completeness of information & & & & & $\mathrm{G}$ \\
\hline Avoiding distractions & $\mathrm{B}$ & $\mathrm{B}$ & $\mathrm{B}$ & $\mathrm{B}$ & \\
\hline Product reviews & & & & $\mathrm{B}$ & \\
\hline Product comparison engines & & & & $\mathrm{B}$ & \\
\hline The ease of using categories & & & & & $\mathrm{G}$ \\
\hline Accuracy of search results & $\mathrm{G}$ & $\mathrm{G}$ & $\mathrm{G}$ & & $\mathrm{B}$ \\
\hline Spellchecker & $\mathrm{B}$ & $\mathrm{B}$ & $\mathrm{B}$ & & \\
\hline Filtering functionality & & & & & $\mathrm{B}$ \\
\hline Additional functionalities & $\mathrm{B}$ & $\mathrm{B}$ & $\mathrm{B}$ & & \\
\hline
\end{tabular}

TABLE II

THE PERCENTAGE ASSESSMENT OF PARTICULAR COMPARISON WEBSITES

\begin{tabular}{|l|c|c|c|c|c|}
\hline Evaluation/Comparison website & Ceneo.pl & Nokaut.pl & Skapiec.pl & Okazje.pl & Other \\
\hline Unsatisfactory & $3.50 \%$ & $4.00 \%$ & $3.45 \%$ & $10.65 \%$ & $\mathbf{4 5 , 6 8 \%}$ \\
\hline Poor & $8.94 \%$ & $18.55 \%$ & $15.36 \%$ & $\mathbf{2 3 . 4 9 \%}$ & $19.14 \%$ \\
\hline Satisfactory & $27.66 \%$ & $32.55 \%$ & $27.12 \%$ & $\mathbf{3 3 . 6 6 \%}$ & $19.14 \%$ \\
\hline Good & $40.95 \%$ & $33.45 \%$ & $\mathbf{4 1 . 3 8 \%}$ & $24.70 \%$ & $9.26 \%$ \\
\hline Very good & $\mathbf{1 8 . 9 6 \%}$ & $11.45 \%$ & $12.70 \%$ & $7.51 \%$ & $6.79 \%$ \\
\hline
\end{tabular}

analogically as presented above (the distance for a particular feature in the same website from the same website is 0 ), values below the diagonal are the converse of the values over the diagonal,

- constructing a module matrix of transformations of the differences of average distance from the maximum value between the websites, for each criterion,

- for each module matrix of transformation of the differences of the average distance from the maximum value between the websites, squaring it, adding up rows, standardization of the obtained ranking vector and repeating this operation until the obtained differences between two ranking vectors for each criterion will be minimal.

As a result of the above presented operations we obtain a conversion matrix of websites' evaluations: using the obtained vectors to construct a combined ranking matrix

- heading names of bank websites by appropriate transfer of the obtained preference vectors for each criterion,

- multiplying the matrix obtained in such a way by the previously calculated preference vector,

- analysing final results and drawing conclusions (Note: the lowest distances in this case are the most favourable, comparability adjustments to other methods can be obtained by subtracting these values from 1 and their repeated standardization).

The basis for the creation of the presented method was the assumption that it should be easy to apply. The objective has been reached, which is visible in the number of the advantages presented below. The only disadvantage of the method is the fact that the transformation of the results of the survey is connected with carrying out many complex operations.

The advantages of this method are:

- the ease of application (similar to the realization of a scoring method) which results from the fact that in the survey form there are questions concerning the subjective evaluation of the element,

- in the case of considering a large number of evaluation criteria or alternatives there is no significant increase in the number of questions in the survey,

- the possibility of the application of the method with the participation of people who are not experts in a given field,

- there are no measures, as in the case of e.g. ELECTRE method - veto threshold, which may not be fully understandable for the respondent [14],

- the result of the calculations which takes the form of the importance of the evaluations of the examined objects.

Similarly to previous cases, the application of a conversion method resulted in flattening of the obtained results. It reduced not only the differences between particular comparison engines but also the differences among particular evaluation criteria. As a result, the obtained findings minimized the subjectivity of the evaluation, and additionally — as it turned out - brought the results closer to the findings of the preliminary analysis of 


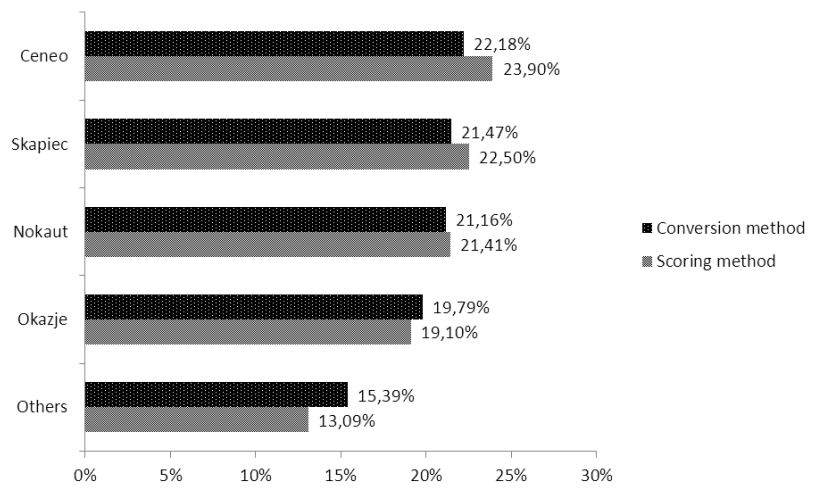

Fig. 2. Ranking of selected comparison engines websites according to a scoring method and a conversion method

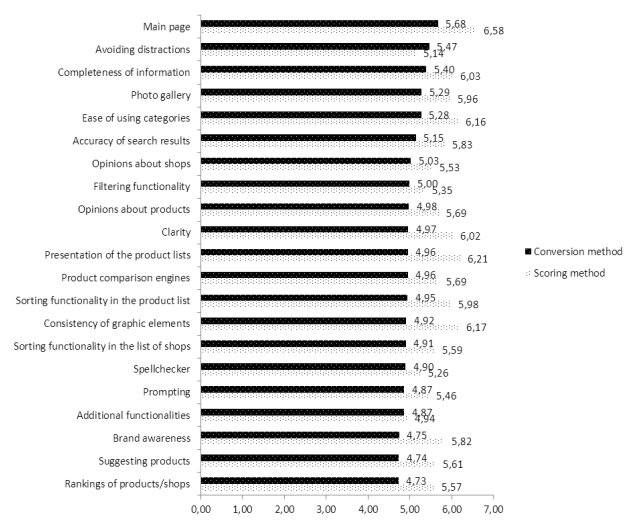

Fig. 3. Ranking of the degree of usefulness of particular criteria in the evaluation of the quality of comparison engines according to a conversion method and a scoring method

the requirements of comparison engines users. Figure 2 shows the results of calculations carried out by means of the scoring method and the conversion method brought to comparability.

In this case the conversion did not bring about any changes in the order of the evaluated comparison engines: it reduced the distance between them in such a way that for the engines which came first in the ranking there occurred differences in minus, and for the last ones in plus. Still, we can conclude that ceneo.pl may be seen as the best service among those selected for the evaluation.

However, there are no regularities with regard to the differentiation of criteria allowing for the detailed evaluation of each website. In this case we noted the reduction of the distances among the criteria. Also, the order of their evaluations changed in a significant way. The first positions were taken by: main page design, avoiding distractions and completeness of information about a product; the last ones were: brand awareness, suggesting products and rankings of products/shops. Only a third of the obtained criteria values exceed the average; thus, we may conclude that only those criteria may be seen as a model to be followed.

\section{CONCLusions}

On the basis of the above results we can create - similarly as in the case of the application of the scoring method - the detailed basic pattern - a prototype which is a compilation of the best features of comparison engines, selected on the basis of the users' evaluations. This prototype should be confronted with the users' expectations established on the basis of their individual preferences.

The obtained findings (see: Table 3) allow for better matching of the results obtained in the rankings by means of conversion method (three times better than in the case of a scoring method). In this case good adaptation does not offer too much room for manoeuvre with regard to the selected evaluation criteria; however, it points to users' awareness of the most important features of the comparison engines.

Particular attention should be paid to those criteria where the discrepancies in the evaluations of the users' expectations and their realisations were the greatest. In subsequent iterations by way of "confrontations" (within the limits established by the obtained pattern), we refine the final prototype, and proceed to the next stage of the project. In the case of the application of a scoring method in the study, the discrepancies were significantly larger and concerned over $50 \%$ of the indicators. In the case of the application of a conversion method they do not exceed $10 \%$. Further studies, however, may show whether there is a regularity resulting from the characteristics of a conversion method or it is just a coincidence.

The research is an extension of the previous one and will be continued. On the basis of the study findings the next method supporting website assessment will be applied. This time AHP/ANP method (T. Saaty) will be used, because it allows to remove (even better then conversion method) subjectivity of evaluations from the respondents questionnaires. Then, the selected methods of assessment websites will be compared with respect to their suitability for use inside a confrontational pattern-based design method. So, the theoretical and methodological achievements of this research will be enhanced and the verification will be conducted on the example of next Polish websites and portals.

\section{REFERENCES}

[1] Buchanan J., Sheppard P., Lamsade D. V. Project ranking using ELECTRE III, at http://130.217.168.130/departments/staff/jtb/Electwp.pdf.

[2] Chmielarz W, Szumski O., Zborowski M.: (2011), Kompleksowe metody ewaluacji witryn internetowych (On Complex Methods of Websites Asessment), Warszawa, Wydawnictwo Wydziału Zarządzania UW, Warsaw.

[3] Chmielarz W. (2013), Zarządzanie projektami@rozwój systemów informatycznych zarządzania (Projrct management@Management Information Systems Development), Wydawnictwo Naukowe WZ UW, Warsaw.

[4] Chmielarz W., Zborowski M.: Conversion Method in Comparative Analysis of e-Banking Services in Poland in: rozdz. 4 pt.: Information Systems and Services in: Perspectives in Business Informatics Research eds. A. Kobyliński, A. Sobczak in: Lecture Notes in Business Information Processing nr 158, Springer Verlag, Berlin, Heidelberg, 2013, str. 227-240.

[5] Chmielarz W. (2014): Confrontational Pattern-Based Design Method realization of service design methods in: proceedings of KM Conference 2014 , in printing. 
TABLE III

THE POSITIONS OF PARTICULAR CRITERIA IN THE EVALUATION OF COMPARISON ENGINES IN THE PRELIMINARY EVALUATION OF THE USERÂĂ REQUIREMENTS AND IN THE EVALUATION RESULTING FROM CALCULATIONS WITH THE APPLICATION OF A SCORING METHOD AND CONVERSION METHOD

\begin{tabular}{|c|c|c|c|c|c|}
\hline Criterion & $\begin{array}{c}\text { Preliminary } \\
\text { analysis }\end{array}$ & $\begin{array}{c}\text { Ranking } \\
\text { according } \\
\text { to a scoring } \\
\text { method (SM) } \\
\end{array}$ & $\begin{array}{l}\text { Ranking } \\
\text { according } \\
\text { to a conversion } \\
\text { method }(\mathrm{CM})\end{array}$ & $\begin{array}{l}\text { The absolute } \\
\text { value of the } \\
\text { difference SM }\end{array}$ & $\begin{array}{l}\text { The absolute } \\
\text { value of the } \\
\text { difference CM }\end{array}$ \\
\hline Main page & 3 & 1 & 1 & 2 & 2 \\
\hline Avoiding distractions & 4 & 21 & 2 & 17 & 2 \\
\hline Completeness of information & 2 & 5 & 3 & 3 & 1 \\
\hline Photo gallery & 5 & 8 & 4 & 3 & 1 \\
\hline Ease of using categories & 6 & 4 & 5 & 2 & 1 \\
\hline Accuracy of search results & 1 & 9 & 6 & 8 & 5 \\
\hline Filtering functionality & 7 & 19 & 7 & 12 & 0 \\
\hline Opinions about products & 10 & 11 & 8 & 1 & 2 \\
\hline Clarity & 8 & 6 & 9 & 2 & 1 \\
\hline Product comparison engines & 11 & 12 & 10 & 1 & 1 \\
\hline Consistency of graphic elements & 9 & 3 & 11 & 6 & 2 \\
\hline Opinions about shops & 12 & 17 & 12 & 5 & 0 \\
\hline Presentation of the product list & 14 & 2 & 13 & 12 & 1 \\
\hline $\begin{array}{l}\text { Sorting functionality } \\
\text { in the product list }\end{array}$ & 13 & 7 & 14 & 6 & 1 \\
\hline $\begin{array}{l}\text { Sorting functionality } \\
\text { in the list of shops }\end{array}$ & 16 & 15 & 15 & 1 & 1 \\
\hline Spellchecker & 17 & 20 & 16 & 3 & 1 \\
\hline Additional functionalities & 20 & 13 & 16 & 7 & 4 \\
\hline Prompting & 15 & 18 & 18 & 3 & 3 \\
\hline Brand awareness & 18 & 10 & 19 & 8 & 1 \\
\hline Suggesting products & 21 & 14 & 20 & 7 & 7 \\
\hline Rankings of products/shops & 19 & 16 & 21 & 3 & 2 \\
\hline
\end{tabular}

[6] Flasiński M. (2006): Zarządzanie projektami informatycznymi (Informatics Project Management), Wydawnictwo Naukowe PWN, Wasaw.

[7] http://epp.eurostat.ec.europa.eu/statistics_explained/index.php/ E-commerce_statistics, listopad 2013.

[8] http://wiadomosci.mediarun.pl/artykul/internet-internet, czy-dzieki-porownywarkom-cen-faktycznie-kupujemy-najtaniej,44430, 2,1,1.html, listopad 2013.

[9] http://www.tradedoubler.com/pl-pl/informacje-i-zasoby/, listopad 2013.

[10] Meroni A., Sangiorgi D., (red.) (2011), Design for Services, Lancaster University, Farnham, Gower.

[11] Nowoczesne zarządzanie projektami (Contemporary Project Management), (2012) red. M. Trocki, PWE, Warsaw.
[12] Orłowski C., Z. Kowalczuk, E. Szczerbicki (2009), Zastosowanie technologii informatycznych w zarządzaniu wiedzą (IT Application in Knowledge Managemnt), PWNT, Gdańsk.

[13] Sikorski M. (2013), Usługi on-line. Jakość, interakcje, satysfakcja klienta (On-line Services. Quality, Interaction, Customer satisfaction), Wydawnictwo Polsko-Japońskiej Wyższej Szkoły Technik Komputerowych, Warszawa.

[14] Zborowski M. (2013), Modelowanie witryn internetowych o profilu ekonomicznym (Economic Universites Profile Websites Modelling), University of Warsaw, Faculty of Management, Warsaw, 2013, doctoral dissertation under the supervision of W. Chmielarz. 